\title{
Risk Factors and Outcome of Overt Stroke in Sickle Cell Patients Admitted in Two Reference Hospitals in Yaounde and Douala
}

\author{
Eposse Ekoube Charlotte1,2, Alima Yanda Anastasie Nicole ${ }^{3,4}$, Ekotto Karen Ingrid1,5, \\ Mandeng Ma Linwa Edgar6*, Ngo Linwa Esther Eleonore5, Mbono Ritha², \\ Djike Puepi Yolande6, Epee Patricia², Dora Mbanya ${ }^{5}$, Mbassi Awa ${ }^{7}$
}

\begin{abstract}
${ }^{1}$ Centre de Prise en Charge des Drépanocytaires, Hôpital Laquintinie, Douala, Cameroun
${ }^{3}$ Institut Supérieur de Technologie Médicale, Yaoundé, Cameroun

${ }^{4}$ Centre Mère Enfant Fondation Chantal BIYA, Yaoundé, Cameroun

${ }^{5}$ Faculty of Health Sciences, University of Bamenda, Bamenda, Cameroun

${ }^{6}$ Faculty of Health Sciences, University of Buea, Buea, Cameroun

${ }^{7}$ Faculté de Médecine et des Sciences Biomédicales, Yaoundé, Cameroun

Email: *macadamcity_2007@yahoo.fr
\end{abstract}

${ }^{2}$ Faculté de Médecine et des Sciences Pharmaceutiques, Université de Douala, Douala, Cameroun

How to cite this paper: Charlotte, E.E. Nicole, A.Y.A., Ingrid, E.K., Edgar, M.M.L., Eleonore, N.L.E., Ritha, M., Yolande, D.P., Patricia, E., Mbanya, D. and Awa, M. (2021) Risk Factors and Outcome of Overt Stroke in Sickle Cell Patients Admitted in Two Reference Hospitals in Yaounde and Douala. Open Journal of Pediatrics, 11, 503-516.

https://doi.org/10.4236/ojped.2021.113047

Received: July 30, 2021

Accepted: September 24, 2021

Published: September 27, 2021

Copyright () 2021 by author(s) and Scientific Research Publishing Inc. This work is licensed under the Creative Commons Attribution International License (CC BY 4.0).

http://creativecommons.org/licenses/by/4.0/

\section{(c) (i) Open Access}

\begin{abstract}
Background: Worldwide, the prevalence of sickle cell disease (SCD) as of 2016 was estimated at $2 \%$; that is 300,000 births annually. This study was focused on homozygous sickle cell disease which leads to several complications notably hemolytic crises, aplastic crises and vaso-occlusive crises like stroke. Sickle cell disease is the most common cause of childhood stroke. Stroke occurs in $17 \%-24 \%$ of sickle cell children worldwide. Objectives: To determine the risk factors for overt stroke and outcome at discharge in sickle cell disease patients admitted in two reference hospitals in Cameroon. Method: This was a case-control study in two reference hospitals in Yaounde and Douala, carried out over the duration of 4 months, covering a 5 -year period (December 2013 to December 2018). Included in the study, were all homozygous sickle cell children aged 6 months to 16 years during that period with or without stroke. A total of 1734 patients fulfilled the inclusion criteria. Out of these, 49 stroke patients participated and 687 were selected as controls. Data was collected from the patients' files and books on a pretested data collection form, then entered in the software C.S Pro 7.1 before analysis. Stroke outcome at discharge was assessed using the modified Rankin scale (mRs) with structured interview. A patient was classified as good outcome if $\mathrm{mRs}<$ 3 and poor outcome if $\mathrm{mRs} \geq 3$. Statistical analysis was done with SPSS software version 22.0 for Windows. Results: A total of 736 patients participated
\end{abstract}


in the study. Out of these, 391 (53.1\%) were males and 345 (46.9\%) were females. Overt stroke was found to have an estimated hospital prevalence of $3.29 \%$ in this population. Several risk and associated factors were identified such as frequent rate of acute chest syndrome $(\mathrm{p}<0.001)$, acute chest syndrome in the past 2 weeks $(\mathrm{p}=0.001)$, low steady state haemoglobin $(\mathrm{p}<$ $0.001)$ and previous stroke $(\mathrm{p}=0.002)$. A poor outcome was observed in 16 $(32.7 \%)$ of them. Conclusion: The occurrence of stroke in this population is $3.29 \%$ and several factors were associated with its occurrence.

\section{Keywords}

Stroke, Prevalence, Risk Factors, Outcome, Modified Rankin Scale

\section{Introduction}

Sickle cell disease (SCD) is a group of inherited haemoglobinopathies [1]. Sickle cell anaemia, which is the most common form of sickle cell disease in Sub-Saharan Africa (SSA) refers specifically to homozygosity for the $\beta$ s allele and is recognised by the World Health Organisation (WHO) as a global public health concern, associated with high morbidity and mortality [2] [3] [4] [5] [6]. In Cameroon, the prevalence of the sickle cell trait is estimated to be $18.2 \%$ for the heterozygous form and $2 \%-3 \%$ for the homozygous SS forms [7].

Sickle cell anaemia is the most common cause of stroke in children [2] [3] [8]. Stroke, which is also known as cerebrovascular accident (CVA) is defined by the Cooperative Study of Sickle Cell Disease (CSSCD) as an acute neurologic syndrome due to vascular occlusion or haemorrhage in which neurologic symptoms lasted more than 24 hours or until death [9]. Approximately 11 percent of children with SCD will have a stroke before age 20 , and without secondary prevention more than half of these will have recurrent stroke within two years of the initial stroke [10] [11]. An estimated prevalence of 7.8\% was found in Jamaica, 9.1\% in Nigeria and $6.7 \%$ in Cameroon [2] [12] [13]. Infarction accounts for $75 \%$ of strokes in SCD and is the most common stroke type in children [14]. The average age for the first recognized cerebral infarct is 7.7 years with most occurring between the ages 5 and 15 years [15].

Several risk factors, as well as associated factors have been identified by the CSSCD: for ischemic stroke, prior transient ischemic attack (TIA), frequency of acute chest syndrome (ACS), ACS in the 2 weeks preceding the event, and systolic blood pressure among others [10] [16]. For haemorrhagic strokes, identified risk factors include older age, low steady state hemoglobin and high steady state leucocyte count [16]. The outcome following stroke in SCD patients depends mainly on the severity of the stroke, the type of stroke, and how prompt the management is taken into action. A study carried out over a 5 -year period by Portnoy et al. revealed that $24.7 \%$ of sickle cell patients developed hemiplegia following their stroke [17]. Deficits in executive function and attention have 
been found in those with overt and silent infarcts too [1]. Mortality rate following a stroke event in under 5 sickle cell children in Sub-Saharan Africa varies greatly from $10 \%$ - 90\% [18] [19].

Very few studies on stroke in sickle cell patients have been carried out in $\mathrm{Ca}$ meroon. We therefore aimed to determine the risk factors for overt stroke and outcome at discharge in sickle cell disease patients followed at two sickle cell treatment centers in Cameroon.

\section{Materials and Methods}

\subsection{Study Design, Period and Setting}

The study was a case-control study. The study was carried out for a period of 4 months from March 2019 to June 2019 but covered a 5-year retrospective data that ranged from December 2013 to December 2018. The study took place in two reference centers for the management of sickle cell disease in 02 different cities, notably the Mother and Child Center of the Chantal Biya's Foundation and the Douala Laquintinie Hospital, in Yaounde and Douala, which are the political and economic capital of Cameroon respectively.

\subsection{Participants and Sampling}

All sickle cell patients who were admitted at LH Douala and MCC-CBF Yaounde and diagnosed of stroke within December 2013 - December 2018 and were homozygous (SS) sickle cell patients aged 6 months - 16 years old, admitted for stroke during the study period were defined as cases while homozygous (SS) sickle cell patients aged 6 months - 16 years old admitted for pathologies other than stroke in these hospitals during the study period were controls. Unusable patient files (files with insufficient relevant data) were excluded from the study [20].

The sample size was calculated using the Schesselman formula for case-control studies and proportions were gotten from a study carried out by Quinn C.T and Sargent J.W, 2007 on daytime steady-state haemoglobin desaturation as a risk factor for overt stroke in children with sickle cell anaemia with 22 cases for 390 controls.

\subsection{Study Procedures, Tools and Variables}

Files corresponding to the year of study were checked thoroughly, and patients with repeated admissions were considered only once, that is, only their first admissions throughout the study period were recorded. The data collected included: age, sex, residence, region of origin, contact, the admission dates, the past history, diagnosis and work ups.

From the data collected from files, not all the information could be found, so the parents of these patients were contacted through phone calls, and after introduction and brief summary of the study, were invited to come to the hospital with the necessary documents which included consultation books and work-up 
results if available. For the parents, whose displacement to the hospital wasn't possible, the appointment was programmed at their place of convenience.

At the meeting, the study procedure along with the information sheet was explained in details to parents in the language which they best understood, either English or French. Consent was then given by the parent/guardian to pursue with the study, by signing a parental consent form.

The consultation books and work-ups brought by the patients were examined, to fill the remaining information such as: frequency of acute chest syndrome, steady state haemoglobin and leucocytes etc.

The patients who had stroke, had their outcome at discharge evaluated by their dependency level for activities of daily living using the modified Rankin Scale.

The modified Rankin Scale (mRS) is a commonly used scale for measuring the degree of disability or dependence in the daily activities of people who have suffered a stroke or other causes of neurological disability. It has become the most widely used clinical outcome measure for stroke clinical trials. Interobserver reliability of the mRS can be improved by using a structured questionnaire during the interview process, which has been used for this study.

\subsection{Operational Definitions}

- Stroke: It was defined as any episode of acute neurological dysfunction presumed to be caused by cerebral ischemia or hemorrhage, persisting for $\geq 24$ hours or until death OR any patient with a working diagnosis of stroke OR any patient with CT-scan confirmed stroke.

- Outcome: The outcome was evaluated as the functional outcome at hospital discharge, for daily activities and mortality. This was assessed by the use of the modified Rankin scale. It is a scale which measures the degree of disability or dependence in the daily activities of sickle cell patients who have suffered a stroke, and includes a score for "death" in its parameters. Modified Rankin Scale score at discharge $<3$ will be considered good outcome and a score of $\geq 3$, will be considered a poor outcome.

\subsection{Data Management and Data Analysis}

Data were collected both from files and using questionnaires. To ensure patient confidentiality, the patient information was coded. The data were then entered at the end of the collection process, from the questionnaires into the computer using CS Pro 7.1 data entry software, after several cross-checks for errors. Data were entered using a double-entry mode and verification was performed using the validate program of the software. The data was then stored in an external hard drive and computer whose passwords were known only to the investigator and collaborators.

The data was analysed using the software statistical package for social sciences (SPSS) version 22.0. Categorical data were presented as frequencies and percen- 
tages. The prevalence of stroke in this population was calculated. We calculated proportions of the variables in both cases and controls, along with their odd's ratio. Risk and corresponding 95\% CI was estimated and the level of significance was set as $\mathrm{p}<0.05$.

\subsection{Ethical Considerations}

Ethical clearance was obtained from the Institutional Review Board of the University of Bamenda. The eligible subjects were contacted and invited to the hospital to fill out the missing data using the medical records in their possession. Their transportation was taken in charge. They were expected to sign an informed consent form prior to participation in the study which stated that they granted us permission to go through those medical records and they had the free will to withdraw from the study at any time without any consequences on their usual follow-up. Administrative authorisation to carry out the research in the two different units at LHD and MCC-CBF was obtained from the directors of these hospitals respectively. Confidentiality, anonymity and privacy of these patients' records were guaranteed throughout the study.

\section{Results}

Out of the 1734 patients admitted during the study period who fulfilled the inclusion criteria, 57 cases of stroke were identified. A total of 1000 files were reviewed, cases included. The corresponding 798 matched controls were selected from these files which made a total of 855 patients. 119 of these patients were excluded with 8 of them being cases and 111 controls because they were either unreachable or refused to participate in the study. Hence, the total number of patients enrolled was 736 with 49 cases and 687 controls. This is depicted in Figure 1.

\subsection{Socio-Demographic Characteristics}

The mean age at SCD diagnosis was 17.4 months in the stroke group and 20.5 months for the no stroke group. The mean age at admission was similar for both groups ( 8.0 years in the stroke group and 7.1 years for the no stroke group). The patients had similar frequencies of admissions and acute chest syndrome episodes per year. Very few patients were from the rural communities. Most patients had been followed up at the Mother and Child Centre, Yaounde. All details are represented in Table 1.

\subsection{The Prevalence of Stroke in Sickle Cell Disease}

A total of 1734 sickle cell patients aged 6 months - 16 years were admitted during the study period, and 57 were diagnosed of stroke (3.29\%).

\subsection{Risk and Associated Factors for Stroke in Sickle Cell Disease}

Bivariate logistic regression showed statistical significance in risk factors like 


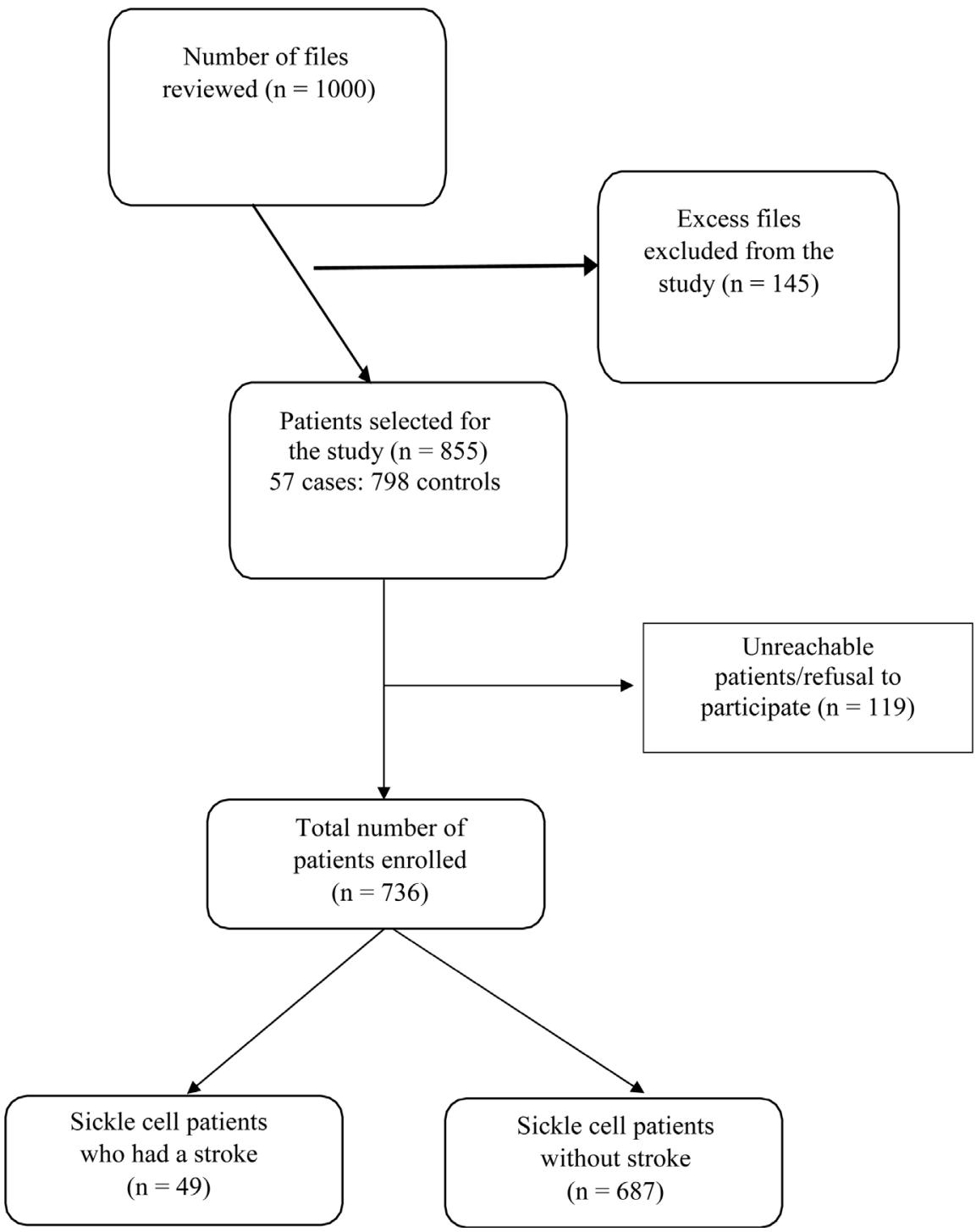

Figure 1. Flow chart of patients.

frequency of acute chest syndrome, recent acute chest syndrome, low steady state haemoglobin, high steady state leucocytes, prior transient ischaemic attack and history of previous stroke which all had a p-value $<0.05$. The multivariate analysis for risk factors of stroke showed that history of acute chest syndrome [OR $=5.545,(2.210-9.911) 95 \% \mathrm{CI}, \mathrm{p}=0.001]$, high steady state leucocytes [OR $=$ 11.284, $(5.728-13.292) 95 \% \mathrm{CI}, \mathrm{p}=0.001$ ], prior TIA [OR $=9.102,(3.362-$ $15.462) 95 \% \mathrm{CI}, \mathrm{p}=0.001$ ], and history of previous stroke [OR $=6.712$, (1.807 8.933) $95 \% \mathrm{CI}, \mathrm{p}=0.004]$, were independent predictors of stroke after adjusting for frequency of acute chest syndrome and low steady state haemoglobin as shown in Table 2 and Table 3.

\subsection{Functional Outcome of Stroke at Discharge in the Study Population}

The functional short-term outcome assessed here was the level of dependency 
Table 1. Sociodemographic characteristics.

\begin{tabular}{lcc}
\hline \multicolumn{1}{c}{ Variable } & Stroke present, $\mathbf{n}=\mathbf{4 9}$ & No stroke $(\%), \mathbf{n}=\mathbf{6 8 7}$ \\
\hline $\begin{array}{l}\text { Mean ( } \pm \text { Standard deviation) } \\
\text { Mean age at admission (in years) }\end{array}$ & $8.04( \pm 3.5)$ & $7.07( \pm 4.0)$ \\
$\begin{array}{l}\text { Mean age at diagnosis of SCD (in } \\
\text { months) }\end{array}$ & $17.4( \pm 15.4)$ & $20.5(15.7)$ \\
$\begin{array}{l}\text { Number of ACS episodes/year } \\
\text { Frequency of admissions/year }\end{array}$ & $3.2( \pm 0.9)$ & $2.7( \pm 0.9)$ \\
$\begin{array}{l}\text { Number (proportions) } \\
\text { Male gender }\end{array}$ & $2.8( \pm 1.1)$ & $2.6( \pm 0.9)$ \\
Rural residence & $26(53.1)$ & $365(53.1)$ \\
$\begin{array}{l}\text { Number of admissions at Mother and } \\
\text { Child Centre }\end{array}$ & $3(5.9)$ & $36(5.4)$ \\
\hline
\end{tabular}

Table 2. Risk and associated factors for stroke in sickle cell disease (univariate analysis).

\begin{tabular}{|c|c|c|c|c|}
\hline Variable & $\begin{array}{c}\text { Stroke } \\
\text { present } \\
(\%), \mathrm{n}=49\end{array}$ & $\begin{array}{c}\text { No stroke } \\
(\%), \mathrm{n}=687\end{array}$ & OR $(95 \% \mathrm{CI})$ & P-value \\
\hline Age (<5 years) & $14(28.6)$ & $288(41.9)$ & $0.554(0.293-1.049)$ & 0.072 \\
\hline Male gender & $26(53.1)$ & $365(53.1)$ & $0.997(0.558-1.782$ & 0.993 \\
\hline $\begin{array}{l}\text { More than } 3 \\
\text { episodes of } \\
\text { ACS/year) }\end{array}$ & $3(6.1)$ & $6(0.9)$ & $7.402(1.793-13.832)$ & 0.018 \\
\hline $\begin{array}{l}\text { Recent ACS } \\
\text { (last } 2 \text { weeks) }\end{array}$ & $13(26.5)$ & $35(5.1)$ & $6.727(3.276-13.815)$ & $<0.001$ \\
\hline $\begin{array}{l}\text { Blood transfusion } \\
\text { (past } 2 \text { weeks) }\end{array}$ & $4(8.2)$ & $14(2.0)$ & $4.171(0.319-12.194)$ & 0.059 \\
\hline Prior TIA & $10(20.4)$ & $19(2.8)$ & $8.331(3.639-10.395)$ & $<0.001$ \\
\hline $\begin{array}{l}\mathrm{HbF} \%(<5 \% \\
\text { of total } \mathrm{Hb})\end{array}$ & $5(10.2)$ & $51(7.4)$ & $1.460(0.550-3.878)$ & 0.399 \\
\hline $\begin{array}{l}\text { Low steady state } \\
\mathrm{Hb}(<6 \mathrm{~g} / \mathrm{dl})\end{array}$ & $25(51.0)$ & $171(24.9)$ & $3.143(1.749-5.649)$ & $<0.001$ \\
\hline $\begin{array}{l}\text { High steady state } \\
\text { leucocytes } \\
\left(>16,000 / \mathrm{mm}^{3}\right)\end{array}$ & $32(65.3)$ & $93(13.9)$ & $12.023(6.419-16.041)$ & $<0.001$ \\
\hline Previous stroke & $6(12.2)$ & $14(2.0)$ & $6.390(2.344-9.873)$ & 0.002 \\
\hline
\end{tabular}

(disability which affects the activities of daily living) at discharge as well as the in-hospital mortality, and the modified Rankin scale was used for this purpose. A great majority of our stroke population had a good outcome at discharge. Out of the 49 stroke patients who participated, 33 (67.3\%) of them had no or very little evident motor deficit, and were able to carry out their daily activities more or less similarly as prior to their stroke, and were defined as having a good outcome while $16(32.7 \%)$ had a poor outcome at discharge with presenting signs like 
Table 3. Multivariate logistic regression for associated/risk factors of stroke.

\begin{tabular}{lcc}
\hline \multicolumn{1}{c}{ Variable } & Adjusted OR $(95 \% \mathrm{CI})$ & Adjusted P-value \\
\hline $\begin{array}{l}\text { More than 3 episodes of acute chest } \\
\text { syndrome }\end{array}$ & $1.528(0.195-8.956)$ & 0.686 \\
$\begin{array}{l}\text { History of acute chest syndrome in the } \\
\text { past 2 weeks. }\end{array}$ & $5.545(2.210-9.911)$ & $\mathbf{0 . 0 0 1}$ \\
Low steady state haemoglobin $(<5 \mathrm{~g} / \mathrm{dl})$ & $1.953(0.983-3.881)$ & 0.056 \\
$\begin{array}{l}\text { High steady state leucocytes }(>16,000) \\
\text { Prior TIA }\end{array}$ & $11.284(5.728-13.292)$ & $\mathbf{0 . 0 0 1}$ \\
Previous stroke & $9.102(3.362-15.462)$ & $\mathbf{0 . 0 0 1}$ \\
\end{tabular}

hemiparesis, aphasia. Only 2 patients from this population died in the hospital, giving a mortality rate of $4.1 \%$. Predictors of poor stroke outcome at discharge in these subjects were determined.

From our study, children aged $>5$ years old and male gender were not found to be statistically significant and were not associated to the course of the outcome (p-values 0.491 and 0.252 respectively). Concerning the interval of more than 12 hours between onset of the stroke and admission to the hospital, as well as the length of hospital stay (>1 week); [OR $=1.056,(0.316-3.522) 95 \% \mathrm{CI}, \mathrm{p}=$ $0.930]$ and $[\mathrm{OR}=2.211,(0.587-8.321) 95 \% \mathrm{CI}, \mathrm{p}=0.235]$, respectively, no association was found either as depicted in Table 4.

Significance was found in the patients who presented with signs and symptoms as aphasia [OR $=9.321,(2.212-19.272) 95 \% \mathrm{CI}, \mathrm{p}=0.001]$ and fever [OR $=$ $3.714,(1.025-4.890) 95 \% \mathrm{CI}, \mathrm{p}=0.040]$, as initial symptom and they were respectively 9.3 and 3.7 times more at risk of having a poor outcome at discharge. The multiple logistic regression for the factors associated with poor outcome showed that aphasia $[\mathrm{OR}=9.988,(2.165-13.072) 95 \% \mathrm{CI}, \mathrm{p}=0.003]$ was an independent predictor for poor outcome of stroke in the study population as shown in Table 5.

\section{Discussion}

Our study population included sickle cell children aged 6 months to 16 years. Majority of patients enrolled were males. Within the "stroke" population, not all patients had a brain CT-scan (mostly because of financial constraints). Of those who could do the scan, all were found to have ischemic strokes. The prevalence of stroke among sickle cell disease patients was found to be $6.7 \%$ in a study carried out in Cameroon [12], 9.1\% in Nigeria and 7.8\% in Jamaica [2] [13]. From our study a prevalence of $3.29 \%$ was found. These disparities might be explained by the difference in study designs used in these studies.

Several factors were assessed to determine any potential association with the occurrence of overt stroke. From this study, no association was found between age below 5 years and occurrence of stroke. Ostendorf A.P et al. in 2017 [14] stated that the age of occurrence of stroke was between 5 and 15 years. This 
Table 4. Prognostic factors for poor stroke outcome (Univariate analysis).

\begin{tabular}{|c|c|c|c|c|}
\hline \multirow{2}{*}{ Variable } & \multicolumn{2}{|c|}{ Modified Rankin Scale } & \multirow{2}{*}{ OR $(95 \% \mathrm{CI})$} & \multirow{2}{*}{$P$-value } \\
\hline & Poor $(\geq 3)$ & Good $(<3)$ & & \\
\hline Age (>5 years) & $30(69.8)$ & $5(83.3)$ & $0.461(0.049-4.348)$ & 0.491 \\
\hline Male gender & $25(58.1)$ & $2(33.3)$ & $2.778(0.458-16.843)$ & 0.252 \\
\hline $\begin{array}{l}\text { Interval between } \\
\text { onset of stroke and } \\
\text { admission (>12 h) }\end{array}$ & $7(43.8)$ & $14(42.4)$ & $1.056(0.316-3.522)$ & 0.930 \\
\hline $\begin{array}{l}\text { Length of hospital } \\
\text { stay (>1 week) }\end{array}$ & $12(75.0)$ & $19(57.6)$ & $2.211(0.587-8.321)$ & 0.235 \\
\hline Aphasia & $9(56.3)$ & $4(12.1)$ & $9.321(2.212-19.272)$ & 0.001 \\
\hline Hemiparesis & $15(93.8)$ & $29(87.9)$ & $2.069(0.282-5.318)$ & 0.524 \\
\hline Seizure & $4(25.0)$ & $6(18.2)$ & $1.500(0.357-6.308)$ & 0.579 \\
\hline Fever & $8(50)$ & $7(21.2)$ & $3.714(1.025-4.890)$ & 0.040 \\
\hline
\end{tabular}

Table 5. Multivariate logistic regression analysis for factors prognostic of poor stroke outcome.

\begin{tabular}{ccc}
\hline Variable & Adjusted OR & Adjusted P-value \\
\hline Aphasia & $9.988(2.165-13.072)$ & $\mathbf{0 . 0 0 3}$ \\
Fever & $4.111(0.936-10.046)$ & 0.061 \\
\hline
\end{tabular}

seems to defend the idea that overt stroke is a disease of the older child. No association was found between stroke occurrence and the male gender. Having had many $(>3)$ episodes of acute chest syndrome in a year or within the last two weeks may predispose someone to overt stroke. Ohene-Frempong et al. [10] also evidenced these as factors associated to the occurrence of stroke. It can be explained by the fact that increase in acute chest syndrome, which is either due to the vaso-occlusion or to infection (pulmonary disease), can lead to hypoxia at the level of the damaged cerebral vessels and precipitate stroke. Strouse J.J found out an association between the use of NSAIDs, a history of blood transfusion in the previous 2 weeks and the occurrence of overt stroke. The author argued that NSAIDs caused bleeding, due to its effect on platelet function, hence haemorrhage was highly possible and blood transfusion had a deleterious effect on the viscosity of blood or the regulation of cerebral blood flow [21]. However, in our study, this association was not found. It can be postulated that this is because our sample had only ischemic strokes.

Patients with SCD typically have HbF levels ranging from $1 \%$ to $20 \%$ and those with genetic mutations leading to hereditary persistence of $\mathrm{HbF}$ (HPFH) can have $\mathrm{HbF}$ levels that reach $30 \%$ to $40 \%$ of the total haemoglobin with a ratio of 1.1:1. Some studies identified haemoglobin $\mathrm{F}$ as a protective factor for stroke [13]. However, this association was not found in our study.

In studies carried out in Nigeria and the USA [10] [22], low steady state haemoglobin, high steady state leucocytes and history of prior TIA have been found 
to have an association with the occurrence of overt stroke, and this correlates with the current study. Sickle cell patients are known to have lower haemoglobin levels and higher leucocytes than non-sicklers. Constant high white blood cell count even when in steady state, can slowly cause damage to the cerebral vessel walls, therefore, increasing the risk for stroke. Conversely, constant low haemoglobin level increases the risk for decreased blood perfusion at the level of the cerebral arteries, hence hypoxia, ischaemia and subsequently stroke. A history of previous stroke was associated with occurrence of a subsequent stroke.

Stroke outcome in our population was assessed using the modified Rankin scale (mRs) structured interview to evaluate dependency of the activities of daily living due to disability. The outcome, which was evaluated at discharge was classified into good and poor outcome. Patients who had "no more symptoms at discharge", or "very slight symptoms which did not affect the daily activities" were classified as good outcome, while patients who had "evident motor deficits", which had an "impact on their daily activities", as well as patients who "died while in the hospital" were classified as poor outcome. From this study, it was found out that the majority $(67.3 \%)$ of the population had a good outcome at discharge. A similar study carried out by Aksu et al., who described the short term neurological outcomes of paediatric stroke, had $61 \%$ of their population with a favorable outcome [23]. Similar results were obtained in 1999 by Edward A. et al. where, $64 \%$ of their study population were totally independent in the activities of daily living at discharge [24]. It could be postulated that the better outcome in children is due to the high plasticity of the child brain. Moreover, most cases of strokes in children are of ischemic types, which are known to have better prognosis than hemorrhagic strokes. Some studies have reported female gender and younger age as risk factors for poor outcome [24], but this association was not found in the current study. Our youngest sickle cell patient with stroke was 4 years old. Young children may not be as handicapped as adults because the injured areas of the brain may not yet be in use [24]. The interval between stroke onset and admission to the hospital, as well as the length of hospital stay were not associated with poor stroke outcome at discharge. Jorgensen H.S. et al. [25], however reported an association between an interval of $>12$ hours between onset of stroke and admission at hospital as a predictor of poor outcome.

Clinical presentation at admission is also highly predictive of the stroke outcome. The most common presentation from our study population was hemiplegia, followed by aphasia. Hemiplegia was similarly found as the most common clinical presentation in a study carried out in Cameroon by Obama et al. [26]. No association was found between the presence of hemiplegia and poor stroke outcome, contrarily to a study carried out by Edward et al. [23]. Aphasia at presentation predicted a poor stroke outcome in our population. Though the type and severity of aphasia was not taken into consideration, several studies show aphasia as being prognostic a sign for poor stroke outcome [27] [28] [29]. 
Aphasia was associated with increased lengths of stay in both the acute stroke and acute rehabilitation settings, more short- and long-term complications, worse performance in activities of daily living, increased financial costs, and increased risk of mortality.

\section{Conclusion}

There was no association between the age of the patient and the occurrence nor outcome of stroke. A prevalence of 3.29\% for stroke in the sickle cell population was found. History of previous stroke, prior TIA, history of acute chest syndrome in the 2 weeks prior to the stroke and high steady state leucocytes are all risk factors for stroke. The mortality rate was low (4.1\%) and majority of our stroke patients had a good outcome at discharge. Aphasia was the only independent factor associated with poor stroke outcome.

\section{Study Limitations}

- The study was retrospective and thus data capture was difficult because of a great amount of missing data. Moreover, since the study was conducted in two central level hospitals, many stroke cases at peripheral level (district hospitals and health centres) and community level could have been missed and thus these results may not be truly representative of the population of Cameroon.

- Many patients with sudden neurological deficit were not able to afford a cerebral CT scan. This gives great bias in our statistical analyses since many cases were clinically diagnosed and no radiological confirmation could be made. Moreover, since outpatients who consulted with neurological deficit were not included in this study, this constitutes another study bias.

\subsection{What Is Known on the Topic}

- In 2006, the estimated prevalence of stroke was found to be $6.7 \%$ in Cameroon.

- No studies on risk factors and outcome of stroke in sickle cell disease have been carried out in Cameroon.

- In a study published in 1994 , the mortality rate was low (2.9\%).

\subsection{What the Study Adds}

- This study enabled us to determine the hospital prevalence (3.29\%) of stroke in the sickle cell population.

- The study was a case-control study, and hence permitted to evaluate the factors which were associated to the occurrence of stroke in our population. History of previous stroke, prior TIA, history of acute chest syndrome in the 2 weeks prior to the stroke and high steady state leucocytes are all risk factors for stroke.

- The mortality rate was low (4.1\%) and majority of our stroke patients had a 
good outcome at discharge.

\section{Acknowledgements}

Authors extend their gratitude to LHD and Centre Mere Enfant Chantal Biya, family and friends and everyone who participated in this research work.

\section{Conflicts of Interest}

The authors declare that they have no competing interests.

\section{Author's Contribution}

EKI collected data from files of patients. EKI, EEC, DM designed the study. EKI and MMLE wrote the manuscript. EEC and DM supervised this work. MMLE, EKI, EEC, DM, MA, NLEE, MR, and NPY contributed to scientifically reviewing the manuscript for intellectual inputs. All authors reviewed the final manuscript and agreed for submission.

\section{References}

[1] Prengler, M., Pavlakis, S.G., Prohovnik, I. and Adams, R.J. (2002) Sickle Cell Disease: The Neurological Complications. Annals of Neurology, 51, 543-552. https://doi.org/10.1002/ana.10192

[2] Marks, L.J., Munube, D., Kasirye, P., Mupere, E., Jin, Z., LaRussa, P., et al. (2018) Stroke Prevalence in Children with Sickle Cell Disease in Sub-Saharan Africa: A Systematic Review and Meta-Analysis. Global Pediatric Health, 5, 1-9. https://doi.org/10.1177/2333794X18774970

[3] Rees, D.C., Williams, T.N. and Gladwin, M.T. (2010) Sickle-Cell Disease. The Lancet, 376, 2018-2031. https://doi.org/10.1016/S0140-6736(10)61029-X

[4] Alima Yanda, A.N., Nansseu, J.R.N., Mbassi Awa, H.D., Tatah, S.A., Seungue, J., Eposse, C., et al. (2017) Burden and Spectrum of Bacterial Infections among Sickle Cell Disease Children Living in Cameroon. BMC Infectious Diseases, 17, 211. https://doi.org/10.1186/s12879-017-2317-9

[5] Makani, J., Williams, T.N. and Marsh, K. (2007) Sickle Cell Disease in Africa: Burden and Research Priorities. Annals of Tropical Medicine \& Parasitology, 101, 3-14. https://doi.org/10.1179/136485907X154638

[6] Mengnjo, M.K., Kamtchum-Tatuene, J., Nicastro, N. and Noubiap, J.J.N. (2016) Neurological Complications of Sickle Cell Disease in Africa: Protocol for a Systematic Review. BMJ Open, 6, e012981. https://doi.org/10.1136/bmjopen-2016-012981

[7] Ama Moor, V.J., Pieme, C.A., Chetcha Chemegne, B., Manonji, H., Njinkio Nono, B.L., Tchoula Mamiafo, C., et al. (2016) Oxidative Profile of Sickle Cell Patients in a Cameroonian Urban Hospital. BMC Clinical Pathology, 16, 15. https://doi.org/10.1186/s12907-016-0037-5

[8] DeBaun, M.R. and Kirkham, F.J. (2016) Central Nervous System Complications and Management in Sickle Cell Disease. Blood, 127, 829-838. https://doi.org/10.1182/blood-2015-09-618579

[9] Adams, R.J., Ohene-Frempong, K. and Wang, W. (2001) Sickle Cell and the Brain. Hematology, 2001, 31-46. https://doi.org/10.1182/asheducation-2001.1.31 
[10] Ohene-Frempong, K., Weiner, S.J., Sleeper, L.A., Miller, S.T., Embury, S., Moohr, J.W., et al. (1998) Cerebrovascular Accidents in Sickle Cell Disease: Rates and Risk Factors. Blood, 91, 288-294.

[11] Powars, D., Wilson, B., Imbus, C., Pegelow, C. and Allen, J. (1978) The Natural History of Stroke in Sickle Cell Disease. The American Journal of Medicine 1978, 65, 461-471. https://doi.org/10.1016/0002-9343(78)90772-6

[12] Njamnshi, A.K., Mbong, E.N., Wonkam, A., Ongolo-Zogo, P., Djientcheu, V.P., Sunjoh, F.L., et al. (2006) The Epidemiology of Stroke in Sickle Cell Patients in Yaounde, Cameroon. Journal of the Neurological Sciences, 250, 79-84. https://doi.org/10.1016/j.jns.2006.07.003

[13] Balkaran, B., Char, G., Morris, J.S., Thomas, P.W., Serjeant, B.E. and Serjeant, G.R. (1992) Stroke in a Cohort of Patients with Homozygous Sickle Cell Disease. The Journal of Pediatrics, 120, 360-366. https://doi.org/10.1016/S0022-3476(05)80897-2

[14] Caplan, L.R. (2017) Primer on Cerebrovascular Diseases. Second Edition, Elsevier, Academic Press, London.

[15] Seeler, R.A. and Royal, J.E. (1977) Acute and Chronic Management of Children with Sickle Cell Anemia and Cerebrovascular Occlusive Crisis. IMJ. Illinois Medical Journal, 151, 267-269.

[16] Webb, J. and Kwiatkowski, J.L. (2013) Stroke in Patients with Sickle Cell Disease. Expert Review of Hematology, 6, 301-316. https://doi.org/10.1586/ehm.13.25

[17] Portnoy, B.A. (1972) Neurological Manifestations in Sickle-Cell Disease: With a Review of the Literature and Emphasis on the Prevalence of Hemiplegia. Annals of Internal Medicine, 76, 643-652. https://doi.org/10.7326/0003-4819-76-4-643

[18] Manci, E.A., Culberson, D.E., Yang, Y.-M., Gardner, T.M., Powell, R., Haynes, J., et al. (2003) Causes of Death in Sickle Cell Disease: An Autopsy Study. British Journal of Haematology, 123, 359-365. https://doi.org/10.1046/j.1365-2141.2003.04594.x

[19] Grosse, S.D., Odame, I., Atrash, H.K., Amendah, D.D., Piel, F.B. and Williams, T.N. (2011) Sickle Cell Disease in Africa. American Journal of Preventive Medicine, 41, S398-S405. https://doi.org/10.1016/j.amepre.2011.09.013

[20] Quinn, C.T. and Sargent, J.W. (2008) Daytime Steady-State Haemoglobin Desaturation Is a Risk Factor for Overt Stroke in Children with Sickle Cell Anaemia. British Journal of Haematology, 140, 336-339. https://doi.org/10.1111/j.1365-2141.2007.06927.x

[21] Strouse, J.J., Hulbert, M.L., DeBaun, M.R., Jordan, L.C. and Casella, J.F. (2006) Primary Hemorrhagic Stroke in Children with Sickle Cell Disease Is Associated with Recent Transfusion and Use of Corticosteroids. Pediatrics, 118, 1916-1924. https://doi.org/10.1542/peds.2006-1241

[22] George, I.O. and Frank-Briggs, A.I. (2011) Stroke in Nigerian Children with Sickle Cell Anaemia. Journal of Public Health and Epidemiology, 3, 407-409.

[23] Uzunhan, T.A., Aydinli, N., Çalişkan, M., Tatli, B. and Özmen, M. (2019) Short-Term Neurological Outcomes in Ischemic and Hemorrhagic Pediatric Stroke. Pediatrics International, 61, 166-174. https://doi.org/10.1111/ped.13737

[24] Hurvitz, E.A. and Beale, L. (1999) Functional Outcome of Paediatric Stroke Survivors. Pediatric Rehabilitation, 3, 43-51. https://doi.org/10.1080/136384999289577

[25] Jørgensen, H.S., Nakayama, H., Raaschou, H.O., Vive-Larsen, J., Støier, M. and Olsen, T.S. (1995) Outcome and Time Course of Recovery in Stroke. Part I: Outcome. The Copenhagen Stroke Study. Archives of Physical Medicine and Rehabilitation, 76, 399-405. https://doi.org/10.1016/S0003-9993(95)80567-2 
[26] Obama, M.T., Dongmo, L., Nkemayim, C., Mbede, J. and Hagbe, P. (1994) Stroke in Children in Yaounde, Cameroon. Indian Pediatrics, 31, 791-795.

[27] Pedersen, P.M., Vinter, K. and Olsen, T.S. (2004) Aphasia after Stroke: Type, Severity and Prognosis. Cerebrovascular Diseases, 17, 35-43.

https://doi.org/10.1159/000073896

[28] Lazar, R.M. and Boehme, A.K. (2017) Aphasia as a Predictor of Stroke Outcome. Current Neurology and Neuroscience Reports, 17, 83.

https://doi.org/10.1007/s11910-017-0797-Z

[29] Nesi, M., Lucente, G., Nencini, P., Fancellu, L. and Inzitari, D. (2014) Aphasia Predicts Unfavorable Outcome in Mild Ischemic Stroke Patients and Prompts Thrombolytic Treatment. Journal of Stroke and Cerebrovascular Diseases, 23, 204-208. https://doi.org/10.1016/j.jstrokecerebrovasdis.2012.11.018 